\title{
Genetic parameters for blood oxygen saturation, body weight and breast conformation in 4 meat-type chicken lines
}

\author{
P. NAVARRO ${ }^{1}$, P.M. VISSCHER ${ }^{1}$, D. CHATZIPLIS ${ }^{2}$, A.N.M. KOERHUIS ${ }^{2}$ AND C.S. HALEY \\ Roslin Institute, Roslin, Midlothian EH25 9PS, Scotland, ${ }^{1}$ Institute of Evolutionary Biology, University of \\ Edinburgh, West Mains Road, Edinburgh EH9 3JT, and ${ }^{2}$ Aviagen Ltd., Newbridge, Midlothian, \\ EH28 8SZ, Scotland
}

\begin{abstract}
The objective of the study was to explore the genetic architecture of blood oxygen saturation $(\mathrm{SaO})$ (an indicator trait, negatively correlated with ascites susceptibility), body weight (Weight) and fleshing score (Flesh, a measure of breast conformation) for 4 meat-type chicken lines reared in commercial conditions.

2. Genetic components, including heritabilities and genetic correlations, were estimated by Restricted Maximum likelihood for these traits measured at 6 weeks of age.

3. Data were collected over eight generations of selection and pedigrees comprised in excess of 130000 birds.

4. Univariate analyses were performed to allow model definition and to obtain starting values for trivariate analyses. The basic model included a random animal effect and, in further models explored, a maternal environmental effect or a genetic maternal effect or both were fitted. Models were compared using likelihood ratio tests.

5. Estimated heritabilities for $\mathrm{SaO}$ ranged from $0 \cdot 1$ to $0 \cdot 2$, and there was no evidence of genetic maternal effects for $\mathrm{SaO}$. The environmental maternal component was significant for one of the populations only. Estimated heritabilities for both Weight and Flesh were between 0.2 and 0.4 , and there was evidence of environmental and genetic maternal effects for these traits in all populations. 6. Genetic correlations between $\mathrm{SaO}$ and Weight and between $\mathrm{SaO}$ and Flesh were low and negative. This suggests that, in principle, genetic selection to simultaneously increase $\mathrm{SaO}$, and therefore decrease ascites susceptibility, and Weight and Flesh could be performed using traditional (marker-free) selection methods. We discuss how a putative interaction between ascites and production traits could jeopardise the success of such methods.
\end{abstract}

\begin{abstract}
Abbreviation $2 \mathrm{LnLR}=$ minus two times the logarithm of the likelihood ratio; $\mathrm{APO}_{2}=$ arterial oxygen pressure; Flesh =fleshing score; $h^{2}=$ heritability; Heart-API = ratio of the weight of the right heart ventricle to total heart weight; $P C V=$ packed cell volume; $\mathrm{SaO}=$ blood oxygen saturation; Weight $=$ body weight; $\sigma_{\mathrm{e}}^{2}=$ residual variance; $\sigma_{\mathrm{em}}^{2}=$ maternal environmental variance; $\sigma_{\mathrm{gm}}^{2}=$ maternal genetic variance; $\sigma_{\mathrm{p}}^{2}=$ phenotypic variance; $\sigma_{\mathrm{u}}^{2}=$ genetic (polygenic) variance;
\end{abstract}

\section{INTRODUCTION}

An increase in the incidence of ascites and ascitesrelated mortality has occurred in broiler populations reared at low altitudes in recent decades (Julian, 1993). During the last 50 years, improvement in production traits (growth, conformation, feed efficiency) through genetic selection has been spectacular (Havenstein et al., 2003) and has been paralleled by an increase in ascites incidence. This, and the fact that fast-growing broilers are more susceptible to suffer from ascites than slow-growing ones (Julian, 1993) has meant that the increase in ascites incidence has been linked to the great genetic improvement in production traits. It is now accepted that ascites susceptibility is, at least partially, under genetic control in certain populations.

Correspondence to: P. Navarro, Institute of Evolutionary Biology, University of Edinburgh, West Mains Road, Edinburgh EH9 3JT, UK. Tel: +44 131650 5442. Fax: +441316506564. E-mail: Pau.Navarro@ed.ac.uk

Accepted for publication 7th September 2005. 
Broiler breeders want to reduce the incidence of the disorder in breeding and commercial flocks and genetic selection against ascites susceptibility provides a more durable means of accomplishing this aim than management solutions, because the benefits of selection accumulate from generation to generation. The study of the genetic basis of ascites, and its relationship with growth traits, in meat-type chicken populations reared in commercial conditions is required in order to implement successful breeding programs that reduce ascites incidence and continue to improve production traits in a sustainable fashion in commercial flocks.

As the presence of ascites can only be confirmed by post-mortem examination (except for severe cases), selection against this disorder has been performed using family information. In recent years, a variety of physiological and anatomical measures have been evaluated as indicators of ascites susceptibility. One of these measures is blood oxygen saturation $(\mathrm{SaO})$, which measures oxygen binding to haemoglobin. Julian and Mirsalimi (1992) showed that broilers suffering from ascites had lower $\mathrm{SaO}$ than fast or slow growing healthy contemporaries and that fast growing healthy birds had lower $\mathrm{SaO}$ than slow growing ones. Wideman et al. (1998) demonstrated that low $\mathrm{SaO}$ predicted susceptibility to ascites and Druyan et al. (1999) showed that $\mathrm{SaO}$ was heritable and that its genetic correlation with ascites mortality was negative in a cold-challenged broiler line. $\mathrm{SaO}$ has the advantage of being easily and non-invasively measured (Wideman et al., 1998) in large numbers of birds that can include selection candidates, which makes it convenient to use in commercial breeding programmes.

In this study, we explored a range of models to estimate the genetic parameters (heritabilities and genetic correlations) for $\mathrm{SaO}$, weight (Weight) and fleshing score (Flesh, a measure of breast conformation) measured at 6 weeks of age in four large pedigrees of different meat-type chicken populations. Some analyses were only performed for line 3 , and this line was chosen to illustrate results because further work was to be carried out on it, because it shows a slightly higher ascites-related mortality than other Aviagen Ltd. lines (A. Koerhuis, personal communication) and it is the heaviest of the lines studied.

\section{MATERIALS AND METHODS}

\section{Data description}

Data on $\mathrm{SaO}$, Weight $(\mathrm{kg})$ and Flesh (1-5 scale) measured at 6 weeks of age, were available for four lines of meat-type chicken. $\mathrm{SaO}$ was directly measured using a pulse oximeter. A sensor was attached to a Criticare Pulse Oximeter 504US ${ }^{1}$ and positioned on the wing to illuminate the tissue between the radius and ulna for measurement of percentage saturation of haemoglobin with oxygen (Julian and Mirsalimi, 1992). When the bird was settled, two readings were taken, and the record for this bird was taken to be an average of both readings. Fleshing is a conformation score with higher scores relating to superior breast muscle development relative to the size of the whole bird. Recording is carried out on handheld terminals grading the birds between 1 and 5,1 being the birds with the least breast meat and 5 the most. Feel of the breast breadth and depth and length of the keel are also taken into account. $\mathrm{SaO}$ data were only available for male selection candidates whereas Weight and Flesh were recorded on all birds. Other information included hatch number (with 224 levels for lines 1, 2 and 3 and 113 levels for line 4), sex and age of dam when the egg was laid (in weeks, with 14 levels).

All 4 lines have been closed for 30 to 40 generations. Lines 1, 2 and 3 have a history of selection on wheat diets whereas line 4 has been selected on a maize diet. Lines 1,3 and 4 are male lines. Line 1 has been selected heavily on efficiency of growth and yield, and some focus has also been put on growth rate; selection for lines 3 and 4 has been more focused on growth rate and efficiency and less line on yield. Line 2 is a female that has been selected on growth rate and efficiency but also on egg production and hatchability. In addition to the aforementioned production traits all lines have been exposed to considerable family selection against broiler mortality and leg defects.

Pedigrees for all lines consisted of around 8 generations that were overlapping for all lines except line 4. Table 1 shows an overview of pedigree and data structure. We considered 'base birds' the first generation of birds available in our pedigrees. These birds were not unrelated or unselected.

The size of the sibships was very variable within and between lines. Family sizes ranged from one to around 100 individuals per full-sib family (with a mean full-sib family size of 25 birds) and from one to around 580 birds per paternal half-sib family (with a mean half-sib family size of 160 birds). Not all birds had SaO data (although all had Weight and Flesh records) and the mean number of males with $\mathrm{SaO}$ data per recorded full-sib and paternal half-sib family was three and 17, respectively. At the time when data were recorded, the overall mortality for these lines was $5-10 \%$ and mortality caused by ascites was part of this proportion. 
Table 1. Pedigree and data structure for blood oxygen saturation ( $\mathrm{SaO}$ ), weight (Weight) and fleshing score (Flesh, a measure of breast conformation) for the four populations

\begin{tabular}{lrrr}
\hline$N$ & Line 1 & Line 2 & Line 4 \\
\hline Birds in pedigree & 179565 & 320550 & 134986 \\
Base generation birds & 1226 & 1421 & 1018 \\
Birds with record for SaO Weight and Flesh & 23134 & 17513 & 11919 \\
Birds with record for Weight and Flesh & 133603 & 318740 & 118782 \\
Sires/paternal half-sib families & 935 & 7174 & 2055 \\
Dams & 5864 & 8500 & 4809 \\
Full-sib families & 7788 & 11560 & 6563 \\
\hline
\end{tabular}

Descriptive statistics of the distributions of $\mathrm{SaO}$, Weight and Flesh were obtained with GENSTAT (GENSTAT 5 COMMITTEE, 1993). In this and the following section, basic results will be presented for all lines but more detailed descriptions will, in some cases, be presented only for line 3 , which is the line for which further studies were carried out.

\section{Genetic analyses}

Genetic parameters were estimated by Restricted Maximum Likelihood in an animal model using ASREML (Gilmour et al., 2000). Fixed effects fitted were hatch number and age of dam for all three traits and sex for Weight and Flesh (because $\mathrm{SaO}$ was only recorded for males). Initially, a series of single trait analyses were carried out for all traits. Four different models were considered:

Model 1 included a random animal effect in addition to a residual term.

Model 2 included a maternal environmental component, modelled as a common dam effect for all maternal half-sibs, in addition to the terms in Model 1.

Model 3 included a maternal genetic component in addition to the terms in Model 1.

Model 4 included a maternal environmental component and a maternal genetic component in addition to the terms in Model 1.

Self and Liang (1987) suggested that, when testing the hypothesis that a parameter has an unspecified positive value versus the hypothesis that this parameter is zero, the asymptotic distribution of -2 times the logarithm of the likelihood ratio (-2LnLR) is a 50:50 mixture of a $\chi^{2}$ with zero degrees of freedom and a $\chi^{2}$ with one degree of freedom. The significance of the maternal environmental and genetic components was tested using this criterion and the best model for each trait was chosen for further (multitrait) analyses. Estimates of variance components from the univariate analyses were used as starting values for variance components for the trivariate analyses. The starting values for the additive, maternal-genetic or environmental-and residual covariances amongst the traits were zero and other covariance components (for example, amongst additive genetic and genetic maternal components) were not estimated.

\section{RESULTS}

\section{Data description}

Table 2 presents the means and standard deviations for the raw phenotypic data for the traits analysed. For all the lines, the distributions of the raw $\mathrm{SaO}$ data were non-Normal (negatively skewed, with skewness coefficients ranging from -0.7 to -0.8 and leptokurtic, with kurtosis coefficients of around 0.5). Figure 1 shows the distribution of $\mathrm{SaO}$ phenotypes for all individuals in the pedigree that had an $\mathrm{SaO}$ record for line 3. Distributions for other lines were similar. Regression lines were fitted to mean $\mathrm{SaO}$ phenotypes for each hatch plotted over time (hatch number) as well as to the first and the third quartiles of each hatch $\mathrm{SaO}$ distribution. These fitted lines show that, over time, mean and first and third quartiles hatch $\mathrm{SaO}$ values increased $(P \leq 0.0001)$. Fitting different regressions for means and quartiles explained the data better than a model for which only one regression coefficient was fitted $(P \leq 0.005)$, and the slope for the first quartile regression was greater than the slope for the mean regression, that was in turn greater than the slope for the third quartile regression. This meant that the variance of $\mathrm{SaO}$ values decreased over time.

The transformation $\operatorname{Ln}(100-x)$, where $x$ is $\mathrm{SaO}$ was found to decrease the skewness of the $\mathrm{SaO}$ distribution (skewness coefficients from -0.3 to $-0 \cdot 4)$. Figure 1 also shows the distribution of the transformed phenotypes for line 3 . Genetic parameters were obtained for both untransformed and transformed $\mathrm{SaO}$ data.

\section{Genetic analyses}

Throughout this section results are only presented for analyses of untransformed $\mathrm{SaO}$ data, because analyses of transformed data yielded 
Table 2. Means and standard deviations (in brackets) for blood oxygen saturation (SaO), weight (Weight) and fleshing score (Flesh, a measure of breast conformation), for the four lines studied, all birds together (All), males (Male) and females (Female)

\begin{tabular}{|c|c|c|c|c|}
\hline Line & & $\mathrm{SaO}(\%)$ & Weight (kg) & Flesh (units) \\
\hline \multirow[t]{3}{*}{1} & All & $79.85(9.38)$ & $2.55(0.30)$ & $3.19(0.91)$ \\
\hline & Male & $79.85(9.38)$ & $2.73(0.26)$ & $3.17(0.91)$ \\
\hline & Female & NA & $2.38(0.22)$ & $3.22(0.90)$ \\
\hline \multirow[t]{3}{*}{2} & All & $82.32(8.52)$ & $2.14(0.29)$ & $3.04(0.87)$ \\
\hline & Male & $82.32(8.52)$ & $2.31(0.26)$ & $3.01(0.88)$ \\
\hline & Female & NA & $1.97(0.22)$ & $3.07(0.86)$ \\
\hline \multirow[t]{3}{*}{3} & All & $80.02(9.15)$ & $2.72(0.34)$ & $3.17(0.92)$ \\
\hline & Male & $80.02(9.15)$ & $2.92(0.29)$ & $3 \cdot 12(0.93)$ \\
\hline & Female & NA & $2.52(0.25)$ & $3.23(0.90)$ \\
\hline \multirow[t]{3}{*}{4} & All & $75.30(8.95)$ & $2.26(0.31)$ & $3.09(0.96)$ \\
\hline & Male & $75.30(8.95)$ & $2.45(0.27)$ & $3.05(0.96)$ \\
\hline & Female & NA & $2.09(0.23)$ & $3.13(0.96)$ \\
\hline
\end{tabular}

NA, not available.

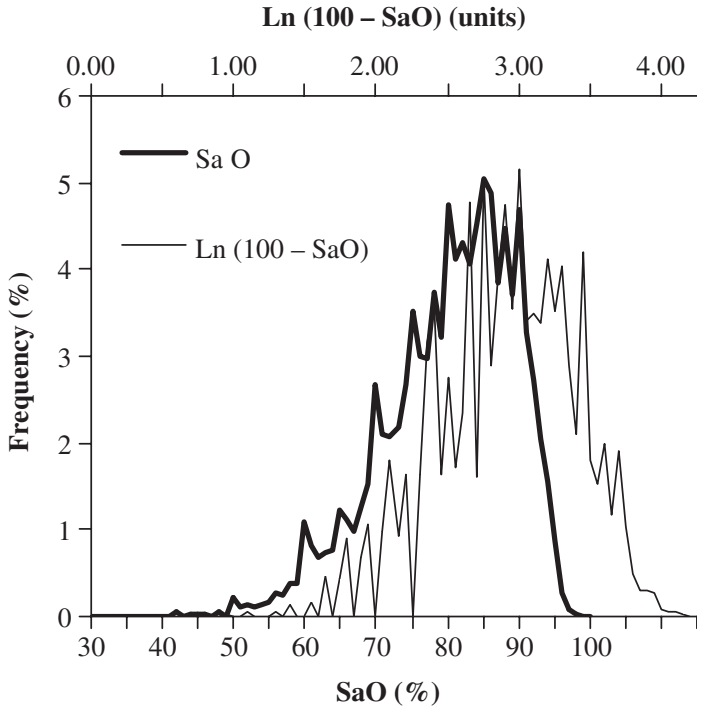

Figure 1. Distribution of blood oxygen saturation $(\mathrm{SaO})$ and Ln (100-SaO) for line 3. Phenotypes of all individuals in the pedigree with $\mathrm{SaO}$ record were used to obtain the distribution.

similar variance ratios and results obtained on the untransformed scale are easier to interpret.

Table 3 shows the estimates of variance components for untransformed $\mathrm{SaO}$ data, Weight and Flesh obtained from univariate analyses for Models 1,2,3 and 4. Estimates obtained for the model chosen for further analyses are shown in bold. For some of the analyses of $\mathrm{SaO}$ data, the maternal genetic component tended to move past the boundary (zero) and was fixed near it. Estimates from these analyses are shown in italics and underlined, and the models that produced them (within line and trait) were not used in further analyses.

Table 4 shows -2LnLR obtained from comparison of different models and an indication of the improvement in fit of the full compared to the reduced model (Model 2 compared to Model 1, etc.). In brief, for Weight and Flesh, the 'best model' for all lines was Model 4, that included both an environmental and a genetic maternal component. For $\mathrm{SaO}$ data, Model 1 was the 'best model' for lines 1, 3 and 4, whereas Model 2 (including an environmental maternal component) was the 'best model' for line 2.

Although the 'best model' for Weight and Flesh for all lines was Model 4, trivariate analyses including a maternal genetic component could not be performed for lines 2 and 4 due to the large size of these pedigrees. Instead results are presented for (trivariate) analyses not including a genetic maternal component but including an environmental maternal component for all traits (line 2) or for Weight and Flesh (line 4).

Table 5 shows heritabilities $\left(h^{2}\right)$, genetic and phenotypic correlations and their standard errors, obtained for (untransformed) $\mathrm{SaO}$, Weight and Flesh. Variance ratios and correlations are also shown for the environmental and genetic maternal components when available. $h^{2}$ for $\mathrm{SaO}$ varied in the range $0 \cdot 12-0 \cdot 21$, the lowest value corresponding to lines 2 and 4 and the highest to line 3. In univariate analyses, only line 2 showed significant environmental maternal effects for $\mathrm{SaO}$, and these explained around $2 \%$ of the total variance. The significance of the maternal environmental component for $\mathrm{SaO}$ was retested in trivariate analyses. The full model included one variance (environmental maternal component for $\mathrm{SaO}$ ) and two covariances more than the reduced model and -2LnLR was therefore compared to a 50:50 mixture of a $\chi^{2}$ with two degrees of freedom and a $\chi^{2}$ with three degrees of freedom (Self and Liang, 1987). The results obtained from these tests were consistent with univariate results.

$h^{2}$ for Weight ranged between 0.26 and 0.41 , the lowest value corresponding to line 3 and the 


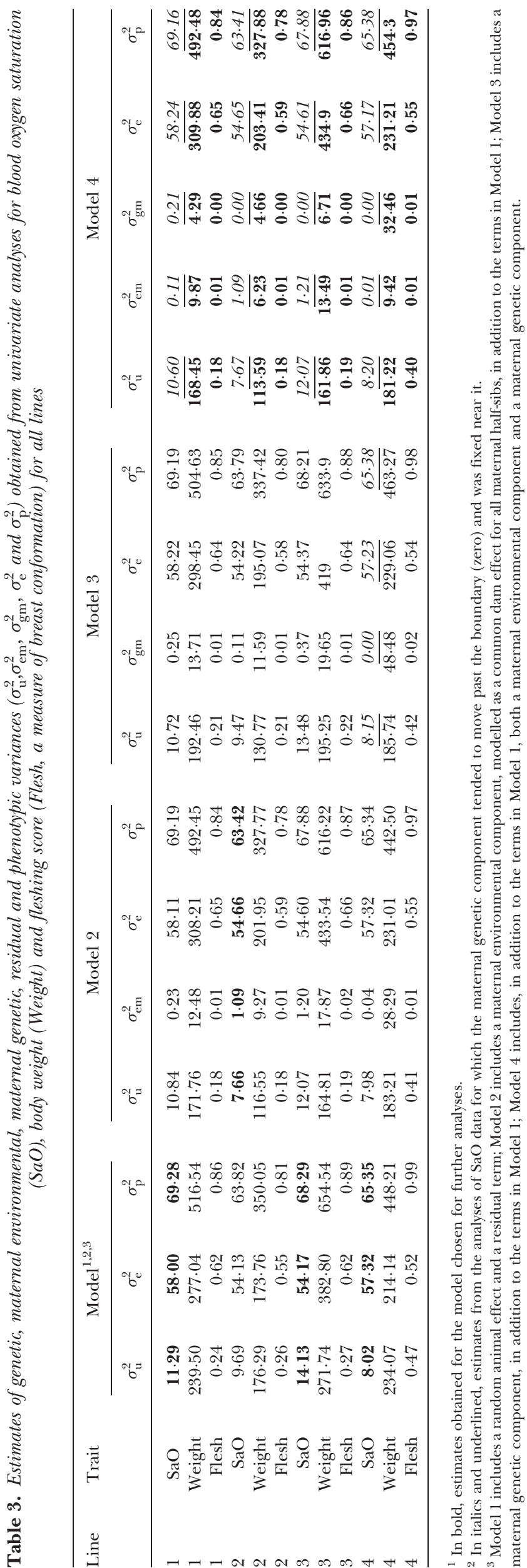


Table 4. Minus two times the logarithm of the likelihood ratio (-2LnLR) and corresponding $P$ values $(P)$ obtained for comparison of models used in univariate analyses for blood oxygen saturation (SaO), body weight (Weight) and fleshing score (Flesh, a measure of breast conformation) for all lines

\begin{tabular}{|c|c|c|c|c|c|c|c|c|c|}
\hline \multirow[t]{2}{*}{ Line } & \multirow[t]{2}{*}{ Trait } & \multicolumn{2}{|c|}{ Model 1 vs. Model $2^{1}$} & \multicolumn{2}{|c|}{ Model 1 vs. Model 3} & \multicolumn{2}{|c|}{ Model 2 vs. Model 4} & \multicolumn{2}{|c|}{ Model 3 vs. Model 4} \\
\hline & & $-2 \mathrm{LnLR}$ & $P$ & $-2 \mathrm{LnLR}$ & $P$ & $-2 \mathrm{LnLR}$ & $P$ & $-2 \mathrm{LnLR}$ & $P$ \\
\hline 1 & $\mathrm{SaO}$ & 0.4 & 0.26 & 0.8 & 0.19 & NA & NA & NA & NA \\
\hline 1 & Weight & 188.0 & $* * *$ & $142 \cdot 0$ & $* * *$ & $16 \cdot 0$ & $* * *$ & $62 \cdot 0$ & $* * *$ \\
\hline 1 & Flesh & 89.8 & $* * *$ & 56.4 & $* * *$ & 8.8 & $* *$ & $42 \cdot 2$ & $* * *$ \\
\hline 2 & $\mathrm{SaO}$ & 7.8 & $* *$ & 0.2 & 0.33 & $\mathrm{NA}$ & NA & NA & NA \\
\hline 2 & Weight & $500 \cdot 0$ & $* * *$ & $520 \cdot 0$ & $* * *$ & 120.0 & $* * *$ & $100 \cdot 0$ & $* * *$ \\
\hline 2 & Flesh & 222.0 & $* * *$ & 160.0 & $* * *$ & 30.0 & $* * *$ & 92.0 & $* * *$ \\
\hline 3 & $\mathrm{SaO}$ & $2 \cdot 1$ & 0.07 & 0.8 & 0.19 & NA & NA & NA & NA \\
\hline 3 & Weight & 162.0 & $* * *$ & 132.0 & $* * *$ & $18 \cdot 0$ & $* * *$ & $48 \cdot 0$ & $* * *$ \\
\hline 3 & Flesh & $82 \cdot 2$ & $* * *$ & $49 \cdot 0$ & $* * *$ & $5 \cdot 2$ & $* *$ & $38 \cdot 4$ & $* * *$ \\
\hline 4 & $\mathrm{SaO}$ & $0 \cdot 0$ & 0.50 & NA & NA & NA & NA & NA & NA \\
\hline 4 & Weight & $1,428 \cdot 0$ & $* * *$ & $1,694 \cdot 0$ & $* * *$ & 302.0 & $* * *$ & $36 \cdot 0$ & $* * *$ \\
\hline 4 & Flesh & 131.2 & $* * *$ & 154.0 & $* * *$ & $47 \cdot 4$ & $* * *$ & $24 \cdot 6$ & $* * *$ \\
\hline
\end{tabular}

${ }^{1}$ Model 1 includes a random animal effect and a residual term; Model 2 includes a maternal environmental component, modelled as a common dam effect for all maternal half-sibs, in addition to the terms in Model 1; Model 3 includes a maternal genetic component, in addition to the terms in Model 1; Model 4 includes, in addition to the terms in Model 1, both a maternal environmental component and a maternal genetic component.

$* * * P \leq 0 \cdot 001$.

$* * P \leq 0 \cdot 01$.

NA, not available.

Table 5. Heritabilities (on diagonals and bold at 'Direct Genetic and Phenotypic' column), genetic and phenotypic correlations (below and above diagonal, respectively) and their standard errors (in brackets), obtained for blood oxygen saturation (SaO), weight (Weight) and fleshing score (Flesh, a measure of breast conformation)

\begin{tabular}{|c|c|c|c|c|c|c|c|c|c|c|}
\hline \multirow[t]{2}{*}{ Line } & \multirow[t]{2}{*}{ Trait } & \multicolumn{3}{|c|}{ Direct Genetic and Phenotypic } & \multicolumn{3}{|c|}{ Maternal Environmental $^{1}$} & \multicolumn{3}{|c|}{ Maternal Genetic } \\
\hline & & $\mathrm{SaO}$ & Weight & Flesh & $\mathrm{SaO}$ & Weight & Flesh & $\mathrm{SaO}$ & Weight & Flesh \\
\hline 1 & $\mathrm{SaO}$ & $\begin{array}{r}\mathbf{0 . 1 7} \\
(0 \cdot 01)\end{array}$ & $\begin{array}{l}-0.00 \\
(0.01)\end{array}$ & $\begin{array}{l}-0.04 \\
(0.01)\end{array}$ & & & & & & \\
\hline 1 & Weight & $\begin{array}{l}-0.17 \\
(0.04)\end{array}$ & $\begin{array}{r}\mathbf{0 . 3 4} \\
(0.01)\end{array}$ & $\begin{array}{r}0.57 \\
(0.00)\end{array}$ & & $\begin{array}{c}0.02 \\
(0.00)\end{array}$ & & & $\begin{array}{c}0.01 \\
(0.00)\end{array}$ & \\
\hline 1 & Flesh & $\begin{array}{l}-0.21 \\
(0.04)\end{array}$ & $\begin{array}{r}0.59 \\
(0.02)\end{array}$ & $\begin{array}{r}\mathbf{0 . 2 2} \\
(0.01)\end{array}$ & & $\begin{array}{c}0.76 \\
(0.05)\end{array}$ & $\begin{array}{c}0 \cdot 01 \\
(0 \cdot 00)\end{array}$ & & $\begin{array}{c}0.87 \\
(0 \cdot 12)\end{array}$ & $\begin{array}{c}0 \cdot 00 \\
(0 \cdot 00)\end{array}$ \\
\hline 2 & $\mathrm{SaO}$ & $\begin{array}{r}\mathbf{0 . 1 2} \\
(0 \cdot 02)\end{array}$ & $\begin{array}{l}-0.02 \\
(0.01)\end{array}$ & $\begin{array}{l}-0.07 \\
(0.01)\end{array}$ & $\begin{array}{r}0.02 \\
(0.00)\end{array}$ & & & & & \\
\hline 2 & Weight & $\begin{array}{l}-0.13 \\
(0.06)\end{array}$ & $\begin{array}{r}\mathbf{0 . 3 5} \\
(0.01)\end{array}$ & $\begin{array}{r}0.58 \\
(0.00)\end{array}$ & $\begin{array}{r}0.00 \\
(0 \cdot 12)\end{array}$ & $\begin{array}{c}0.03 \\
(0 \cdot 00)\end{array}$ & & & & \\
\hline 2 & Flesh & $\begin{array}{l}-0.11 \\
(0.06)\end{array}$ & $\begin{array}{r}0.64 \\
(0.01)\end{array}$ & $\begin{array}{r}\mathbf{0 . 2 4} \\
(0.01)\end{array}$ & $\begin{array}{l}-0.07 \\
(0.13)\end{array}$ & $\begin{array}{c}0.90 \\
(0.02)\end{array}$ & $\begin{array}{c}0.02 \\
(0.00)\end{array}$ & & & \\
\hline 3 & $\mathrm{SaO}$ & $\begin{array}{r}0.21 \\
(0.02)\end{array}$ & $\begin{array}{r}0.01 \\
(0.01)\end{array}$ & $\begin{array}{l}-0.04 \\
(0.01)\end{array}$ & & & & & & \\
\hline 3 & Weight & $\begin{array}{l}-0.02 \\
(0.06)\end{array}$ & $\begin{array}{r}\mathbf{0 . 2 6} \\
(0.01)\end{array}$ & $\begin{array}{r}0.57 \\
(0.00)\end{array}$ & & $\begin{array}{c}0.02 \\
(0 \cdot 00)\end{array}$ & & & $\begin{array}{c}0.01 \\
(0 \cdot 00)\end{array}$ & \\
\hline 3 & Flesh & $\begin{array}{l}-0.10 \\
(0.06)\end{array}$ & $\begin{array}{r}0.53 \\
(0.03)\end{array}$ & $\begin{array}{r}\mathbf{0 . 2 2} \\
(0.01)\end{array}$ & & $\begin{array}{c}0.68 \\
(0.00)\end{array}$ & $\begin{array}{c}0.01 \\
(0.00)\end{array}$ & & $\begin{array}{c}0.77 \\
(0.00)\end{array}$ & $\begin{array}{c}0.00 \\
(0 \cdot 00)\end{array}$ \\
\hline 4 & $\mathrm{SaO}$ & $\begin{array}{r}\mathbf{0 . 1 2} \\
(0.02)\end{array}$ & $\begin{array}{l}-0.02 \\
(0.01)\end{array}$ & $\begin{array}{l}-0.05 \\
(0.01)\end{array}$ & & & & & & \\
\hline 4 & Weight & $\begin{array}{l}-0 \cdot 17 \\
(0 \cdot 07)\end{array}$ & $\begin{array}{r}\mathbf{0 . 4 1} \\
(0.01)\end{array}$ & $\begin{array}{r}0.38 \\
(0.00)\end{array}$ & & $\begin{array}{c}0.06 \\
(0 \cdot 00)\end{array}$ & & & & \\
\hline 4 & Flesh & $\begin{array}{l}-0.15 \\
(0.06)\end{array}$ & $\begin{array}{r}0.31 \\
(0.02)\end{array}$ & $\begin{array}{r}\mathbf{0 . 4 1} \\
(0.01)\end{array}$ & & $\begin{array}{c}0.62 \\
(0 \cdot 00)\end{array}$ & $\begin{array}{c}0.02 \\
(0.00)\end{array}$ & & & \\
\hline
\end{tabular}

\footnotetext{
${ }^{1}$ Variance ratios and correlations are presented for the environmental and genetic maternal components when relevant.
}

highest to line 4 . The inclusion of both environmental and genetic maternal effects improved significantly the fit of the model in univariate analyses, and these components explained between 2 and $6 \%$ and $1 \%$ of the total variance, respectively (the genetic maternal component was only available for lines 1 and 3). Line 4 was the one for which the environmental maternal component explained the largest proportion of variance compared to other lines. 
Table 6. Estimates of genetic, maternal environmental, maternal genetic, residual and phenotypic variances $\left(\sigma_{\mathrm{u}}^{2}, \sigma_{\mathrm{em}}^{2}, \sigma_{\mathrm{gm}}^{2}, \sigma_{\mathrm{e}}^{2}\right.$ and $\sigma_{\mathrm{p}}^{2}$ ) obtained from trivariate analyses for blood oxygen saturation (SaO), body weight (Weight) and fleshing score (Flesh, a measure of

\begin{tabular}{|c|c|c|c|c|c|c|}
\hline Line & Trait & $\sigma_{\mathrm{u}}^{2}$ & $\sigma_{\mathrm{em}}^{2}$ & $\sigma_{\mathrm{gm}}^{2}$ & $\sigma_{\mathrm{e}}^{2}$ & $\sigma_{\mathrm{p}}^{2}$ \\
\hline 1 & $\mathrm{SaO}$ & 11.53 & NA & NA & 57.88 & 69.41 \\
\hline 1 & Weight & $1.66 \times 10^{-02}$ & $1.03 \times 10^{-03}$ & $4.08 \times 10^{-04}$ & $3 \cdot 11 \times 10^{-02}$ & $4.91 \times 10^{-02}$ \\
\hline 1 & Flesh & $0 \cdot 19$ & 0.01 & 0.00 & $0 \cdot 64$ & $0 \cdot 85$ \\
\hline 2 & $\mathrm{SaO}$ & 7.97 & 1.09 & NA & $54 \cdot 61$ & 63.67 \\
\hline 2 & Weight & $1.15 \times 10^{-02}$ & $9.47 \times 10^{-04}$ & NA & $2.03 \times 10^{-02}$ & $3.27 \times 10^{-02}$ \\
\hline 2 & Flesh & $0 \cdot 19$ & 0.01 & NA & 0.58 & 0.79 \\
\hline 3 & $\mathrm{SaO}$ & $14 \cdot 37$ & NA & NA & 54.06 & 68.43 \\
\hline 3 & Weight & $1.59 \times 10^{-02}$ & $1.38 \times 10^{-03}$ & $6.80 \times 10^{-04}$ & $4.36 \times 10^{-02}$ & $6 \cdot 16 \times 10^{-02}$ \\
\hline 3 & Flesh & $0 \cdot 19$ & 0.01 & 0.00 & $0 \cdot 66$ & $0 \cdot 87$ \\
\hline 4 & $\mathrm{SaO}$ & 8.09 & NA & NA & 57.34 & 65.43 \\
\hline 4 & Weight & $1.81 \times 10^{-02}$ & $2.88 \times 10^{-03}$ & NA & $2.32 \times 10^{-02}$ & $4.42 \times 10^{-02}$ \\
\hline 4 & Flesh & 0.40 & 0.01 & NA & 0.55 & 0.96 \\
\hline
\end{tabular}

NA, not available.

$h^{2}$ for Flesh was approximately in the same range as $h^{2}$ for Weight and its lowest value (0.22) corresponded to lines 1 and 3 , the highest $(0.41)$ corresponding to line 4. Environmental and genetic maternal effects jointly explained less than $3 \%$ of the total variance for this trait.

Genetic correlations of $\mathrm{SaO}$ with Weight were low and negative (between -0.17 and $-0.02)$ for all lines and were not significantly different from zero for line $3(P \geq 0 \cdot 05)$. Genetic correlations of $\mathrm{SaO}$ with Flesh were approximately in the same range and were not significantly different from zero for lines 2 and 3 $(P \geq 0 \cdot 05)$. Genetic correlations between the two production traits were positive and moderate to high, (from 0.31 for line 4 to 0.64 for line 2). Correlations of environmental and genetic maternal effects were generally high between these two traits and approached unity in some cases.

Table 6 shows the estimates of genetic, maternal environmental, maternal genetic, and residual and phenotypic variances $\left(\sigma_{\mathrm{u}}^{2}, \sigma_{\mathrm{em}}^{2}, \sigma_{\mathrm{gm}}^{2}, \sigma_{\mathrm{e}}^{2}\right.$ and $\sigma_{\mathrm{p}}^{2}$, respectively) obtained from trivariate analyses for $\mathrm{SaO}$, Weight and Flesh for all lines studied. The fact that the estimated $h^{2}$ of $\mathrm{SaO}$ for line 3 was almost twice the value estimated for lines 2 and 4 reflects differences in estimated $\sigma_{\mathrm{u}}^{2}$ rather than differences in $\sigma_{\mathrm{e}}^{2} \cdot \sigma_{\mathrm{e}}^{2}$ for Weight appeared to be greater for line 3 than for other lines and this was reflected in a lower estimated $h^{2}$ for this line. The estimated $\sigma_{\mathrm{u}}^{2}$ for Flesh was almost double for line 4 than for the other lines, and $h^{2}$ of Flesh for this line was twice the value estimated for the others.

The heritabilities obtained when performing the analysis using transformed $\mathrm{SaO}$ phenotypes did not differ from the ones obtained from untransformed data and are therefore not presented. Due to the nature of the transformation, genetic and phenotypic correlations of $\mathrm{SaO}$ with Weight and Flesh were different in sign but not different in magnitude.

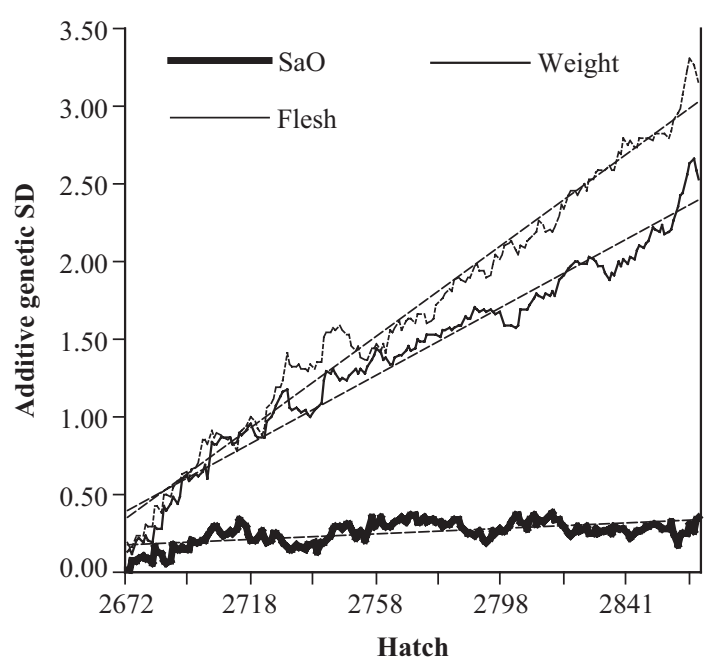

Figure 2. Mean additive value for each hatch (shown in additive standard deviation (SD) units) for blood oxygen saturation, weight and fleshing score, obtained for line 3. Regression equations of fitted lines (- - -) are:

$$
\begin{aligned}
S a O & =0.001 x+0.174\left(R^{2}=0.357\right) \\
\text { Weight } & =0.011 x+0.385\left(R^{2}=0.961\right) \\
\text { Flesh } & =0.015 x+0.335\left(R^{2}=0.982\right) .
\end{aligned}
$$

Figure 2 shows the mean additive value (in additive standard deviations) for $\mathrm{SaO}$, Weight and Flesh for each hatch for line 3. Estimated breeding values from all birds in the pedigree (not only the ones with records for $\mathrm{SaO}$ ) were used to obtain the graph. Figure 2 shows that, although mean hatch values increased over time for all three traits, the rate of increase was a greater for Flesh and Weight than for $\mathrm{SaO}$.

\section{DISCUSSION}

We have demonstrated that there was substantial genetic variation $\left(h^{2}\right.$ of $\left.0 \cdot 1-0 \cdot 2\right)$ for $\mathrm{SaO}$ in the 
four populations studied and therefore genetic selection on this trait is feasible. Although a slightly higher heritability and additive genetic variance was obtained for $\mathrm{SaO}$ in line 3 , in general the estimates of variances, heritabilities and genetic correlations with Weight and Flesh are consistent across lines. Druyan et al. (1999) obtained estimates of $h^{2}$ for $\mathrm{SaO}$ of around $0 \cdot 5-0 \cdot 6$. Unlike our populations, the population Druyan et al. (1999) used in their study was coldchallenged, and this is common in studies of ascites-related traits (see Table 7), with few exceptions (e.g., Moghadam et al., 2001). Rearing birds in challenging environments increases the incidence of the disorder and therefore facilitates selection against it. Table 7 shows heritabilities of a selection of ascitesrelated traits and genetic correlations with body weight from published studies. All traits presented are heritable, but estimates of heritabilities varied widely across studies for similar traits. Moghadam et al. (2001) estimated that $h^{2}$ for ascites mortality obtained from male data alone were higher than the ones obtained jointly from male and female data.

The heritabilities obtained for body weight are similar to the ones reported in the literature (0.2-0.4) (Dunnington and Siegel, 1996; Koerhuis and Thompson, 1997). Despite decades of selection on growth or body weight, genetic variation has not been depleted for these (Rose, 1997) or related traits such as feed conversion (Emmerson, 1997); heritabilities are still moderate to high in contemporary broiler strains and have not diminished markedly compared with earlier estimates (Hill, 1996). The estimates of $h^{2}$ obtained for Flesh were of the same size of those for body weight, and although selection on this trait has not been taking place for as long as for growth traits, the maintenance of this level of genetic variation is also remarkable.

Hill (1996) suggested that mutational variance could be an important source of new genetic variation. Also, the fact that there is still genetic variation may support the idea that many genes with very small effects influence those characters. Alternatively, the mode of action of individual genes, directly on these production traits or indirectly through actions on fitness traits, and interactions amongst loci could explain that genetic variation is maintained; Hill (2002) also pointed out that, under certain circumstances, selection favoured most variable genotypes. Breeding strategies also influence changes of genetic variance over time: for example, new variation could be brought in by the incorporation to the population of immigrants from different lines and fixation of unfavourable alleles could be prevented in this way; this influence could as well be through the selection strategy implemented, for instance

Table 7. Selection of ascites-related traits and estimates of their heritabilities and genetic correlations with body weight $\left(\mathrm{r}_{g} \mathrm{~W}\right)$

\begin{tabular}{|c|c|c|c|c|c|}
\hline Trait $^{1}$ & Heritability & $r_{\mathrm{g}} \mathrm{W}$ & Cold $?^{2}$ & Comments & $\operatorname{Ref}^{3}$ \\
\hline \multirow[t]{4}{*}{ Ascites mortality } & 0.11 to 0.44 & NA & Yes & & 1 \\
\hline & $0 \cdot 06$ & NA & Yes & & 2 \\
\hline & 0.12 to 0.21 & NA & No & Data on males and females & 3 \\
\hline & $0 \cdot 22$ to 0.41 & 0.22 to 0.35 & No & Data on males & 3 \\
\hline \multirow[t]{3}{*}{ Total mortality } & $0 \cdot 22$ & -0.46 & Yes & & 2 \\
\hline & $0 \cdot 16$ & NA & Yes & Maternal genetic effects significant & 4 \\
\hline & $0 \cdot 32$ & $-0 \cdot 06$ & Yes & Maternal genetic effects not considered & 5 \\
\hline \multirow[t]{6}{*}{ Heart-API } & 0.21 to 0.27 & NA & Yes & & 1 \\
\hline & 0.54 & $-0 \cdot 26$ & Yes & & 2 \\
\hline & $0 \cdot 28$ & NA & Yes & Maternal genetic effects significant & 4 \\
\hline & $0 \cdot 45$ & $-0 \cdot 27$ & Yes & Maternal genetic effects not considered & 5 \\
\hline & $0 \cdot 12$ & $0 \cdot 50$ & No & Maternal genetic effects not considered & 5 \\
\hline & 0.42 to 0.72 & NA & Yes & & 6 \\
\hline \multirow[t]{5}{*}{ PCV } & 0.5 & $-0 \cdot 54$ & Yes & & 2 \\
\hline & 0.5 & NA & Yes & & 4 \\
\hline & $0 \cdot 46$ & $-0 \cdot 23$ & Yes & Maternal genetic effects not considered & 5 \\
\hline & $0 \cdot 17$ & 0.55 & No & Maternal genetic effects not considered & 5 \\
\hline & 0.74 to 0.88 & NA & Yes & & 6 \\
\hline $\mathrm{SaO}$ & 0.53 to 0.63 & NA & Yes & & 6 \\
\hline $\mathrm{APO}_{2}$ & $0 \cdot 13$ & $0 \cdot 12$ & Yes & & 2 \\
\hline Troponin $\mathrm{T}$ & $0 \cdot 38$ & NA & NA & & 7 \\
\hline Heart rate & 0.52 to 0.69 & NA & Yes & & 6 \\
\hline
\end{tabular}

${ }^{1}$ Heart-API, ratio of the weight of the right heart ventricle to total heart weight; PCV, packed cell volume; SaO, blood oxygen saturation; APO ${ }_{2}$, arterial oxygen pressure (related with $\mathrm{SaO}$ ).

${ }^{2}$ Cold?, Was the population cold-challenged?

${ }^{3}$ Reference key: 1, Lubritz et al. (1995); 2, De Greef et al. (2001); 3, Moghadam et al. (2001); 4, Pakdel et al. (2002); 5, Pakdel et al. (2005); 6, Druyan et al. (1999); 7, Maxwell et al. (1998).

NA, not available. 
the use of mass selection during the early years of the poultry breeding industry may have contributed to maintain high effective population sizes (Hill, 1996).

The expression of some traits is influenced by the ability of the individual's dam to provide a suitable environment. This ability can be partly environmental and partly genetic. For birds reared in commercial conditions, this influence is mostly reduced to the quality and composition of the egg. Pakdel et al. (2002) and Koerhuis and Thompson (1997) demonstrated, respectively, the significance of genetic maternal effects on ascites related traits and environmental and genetic maternal effects on body weight. In our study, the inclusion of a maternal environmental component for $\mathrm{SaO}$ only improved significantly the fit of the model for line 2. The structure of our $\mathrm{SaO}$ data may have had an impact on our results: a large proportion (around 30\%) of maternal half-sib families were of size one, and the mean maternal family size for $\mathrm{SaO}$ data was around three. Datasets with larger maternal family sizes could facilitate a better estimation of environmental maternal effects for $\mathrm{SaO}$ and allow exploration of the existence of genetic maternal effects for this trait in our populations. Significance of the maternal environmental component was re-tested in trivariate analyses yielding similar results to the ones obtained in univariate analyses. In the case of Pakdel et al. (2002), although the genetic maternal component explained under $5 \%$ of the total variance for all traits, its inclusion in the analysis model had a large impact on the estimated heritability, halving it for most traits, and the correlation of the additive and the maternal genetic components was moderate or high depending on the traits. In our case, although the inclusion of a maternal environmental component slightly decreased heritability of $\mathrm{SaO}$ for line 2, this decrease was only small, as was the decrease in estimated additive genetic variance. Maternal family sizes for Weight and Flesh data were considerably greater than for $\mathrm{SaO}$ data, allowing for the estimation of both environmental and genetic maternal effects.

Koerhuis and Thompson (1997) estimated that environmental and genetic maternal effects explained, respectively, fewer than 10 and $5 \%$ of the total variance for juvenile body weight. In their case, environmental maternal effects were divided into both common maternal half-sib effects and common full-sib family effects. Our results show that both heritable and non-heritable maternal effects are significant for both Weight and Flesh, although the percentage of the total variance explained jointly by these effects was less than $10 \%$ for both traits across lines. Their inclusion in the analysis model reduced estimated heritabilities generally more markedly for Weight than for Flesh. We attempted to estimate the correlation between the direct additive (that is, animal) component and the genetic maternal component, but in the cases where the size of the pedigree allowed the analyses to be run, those failed to converge and therefore no results have been presented. For lines 2 and 4, multitrait analyses including a genetic maternal component could not be run and results were presented instead for analyses including only an environmental genetic component. This, most likely implies that $\sigma_{\mathrm{em}}^{2}$ would be overestimated and would include part of $\sigma_{\mathrm{gm}}^{2}$. Based on results from univariate analyses, genetic maternal effects would be larger than environmental ones for line 4 but approximately of the same size for line 2.

Since ascites is a production-related disorder caused by high oxygen requirements of rapid growth, one would expect a positive correlation between growth-related traits and incidence of the disorder. The sign of our estimates of genetic correlations between $\mathrm{SaO}$ and Weight and Flesh meets the expectation because $\mathrm{SaO}$ is negatively correlated with ascites susceptibility. Nevertheless, the estimated correlations of $\mathrm{SaO}$ with production traits were relatively low, suggesting that selection to increase $\mathrm{SaO}$ (and therefore reduce ascites susceptibility) and production traits simultaneously would be possible in the populations studied. Correlations of other ascites indicator traits with body weight are shown in Table 7 . These correlations are not always consistent with expectations. For instance, De Greef et al. (2001) estimated negative genetic correlations between body weight and total mortality and ratio of the weight of the right heart ventricle to total heart weight (heart-API) and these traits are highly positively correlated with ascites mortality or presence. The authors argued that the sign of their estimated correlations was not as expected because genetic correlation estimates are affected by the presence of the disorder and that this effect depends on the proportion of affected individuals. They suggested that this phenomenon can be viewed as a genotype $\mathrm{x}$ environment interaction, in which the internal environment of the bird (ascites presence or absence) might affect the ability of fast growing animals to fully express their growth potential, so they would show below-average growth. At the same time, changes in metabolic pressure caused by increased growth trigger the 
presence of the disorder in genetically prone birds that would not be affected if growth were somehow controlled by management practices and growth acts as an internal environment that affects ascites presence. These ideas were previously suggested by Julian (1993). To check their hypothesis, they analysed a subset of data containing only animals not affected with ascites (the dataset was divided on the basis of heart-API observed values). The sign of the correlation obtained from this data set changed, meeting their original expectations. Pakdel et al. (2005) estimated genetic correlations between body weight and several ascites-related traits from both a cold-challenged and a noncold-challenged population. Their estimated correlations between body weight and heartAPI and body weight and packed cell volume (PCV) were different in sign depending on the population they were estimated from (coldchallenged or not). They argue that the same phenomena described by De Greef et al. (2001) could be responsible for this observation. Because our populations were not cold-challenged, presumably the incidence of the disorder was lower than for the population studied by De Greef et al. (2001) and the effect on estimated genetic correlations would be smaller. To check the effect that estimating genetic correlations from subsets of potentially ascitic (with low $\mathrm{SaO}$ records) and non-ascitic birds had in our case we focused on line 3 and divided the dataset into subsets of 'ascitic' (with $\mathrm{SaO}$ records lower than 60 or 75) and 'non-ascitic' birds (with $\mathrm{SaO}$ records higher than $60,80,90$ or 95 ). For these analyses, the complete pedigrees were used and phenotypic records below or above the selected cut-off points were omitted. Table 8 shows estimates of heritabilities and genetic correlations for these analyses.

Although estimated heritabilities of production traits and genetic correlations amongst them were similar for all subsets, this was not the case for $\mathrm{SaO}$ and correlations of this trait with Flesh and Weight (N.B. these correlations were not different from zero $(P \geq 0.05)$ in any case, possibly due to the small sample size of some subsets). Estimated heritabilities for $\mathrm{SaO}$ varied across subsets, and were close to zero for subsets of birds with $\mathrm{SaO}$ records smaller than $75 \%$ or greater than $80 \% \mathrm{SaO}$. For subsets with $\mathrm{SaO}$ records greater than $80 \%$, the expected sign of the correlation with production traits would be negative (given that the expected sign of the genetic correlation between production and ascites incidence would be positive and $\mathrm{SaO}$ is negatively correlated with ascites incidence), and this was not observed. The estimated genetic correlations of $\mathrm{SaO}$ with production traits obtained from the subset of birds with less than $60 \% \mathrm{SaO}$ were positive (as expected for affected birds) and moderate (apparently larger than the one estimated from the whole dataset, but caution must be taken in the interpretation of this result given the large standard error of the estimate). In conclusion, the proportion of susceptible birds (assigned on the basis of $\mathrm{SaO}$ records) seems to have an effect on the estimated genetic correlations between $\mathrm{SaO}$ and production traits, but no clear trends were identified, and differences in sample size of the different subsets make results still more difficult to interpret. These analyses are also difficult to

Table 8. Estimates and standard errors of heritabilities for blood oxygen saturation (SaO), weight (Weight) and fleshing score (Flesh, a measure of breast conformation) $\left(\mathrm{h}^{2} S, \mathrm{~h}^{2} W\right.$ and $\left.\mathrm{h}^{2} F\right)$ and genetic correlations amongst these traits $\left(\mathrm{r}_{g} S W\right.$ is the correlation between $\mathrm{SaO}$ and Weight, $\mathrm{r}_{g} S F$ is the correlation between $\mathrm{SaO}$ and Flesh and $\mathrm{r}_{g} W F$ is the correlation between Weight and Flesh) obtained from different subsets of data from line 3

\begin{tabular}{|c|c|c|c|c|c|c|c|c|}
\hline Data & Cut-off $\mathrm{SaO}^{1}$ & $n$ & $r_{\mathrm{g}} \mathrm{SW}$ & $r_{\mathrm{g}} \mathrm{SF}$ & $r_{\mathrm{g}} \mathrm{WF}$ & $h^{2} \mathrm{~S}$ & $h^{2} \mathrm{~W}$ & $h^{2} \mathrm{~F}$ \\
\hline \multirow[t]{2}{*}{ Ascites susceptible } & $<60 \%$ & 315 & $\begin{array}{c}0 \cdot 30 \\
(0 \cdot 36)\end{array}$ & $\begin{array}{c}0 \cdot 37 \\
(0 \cdot 38)\end{array}$ & $\begin{array}{c}0.48 \\
(0.03)\end{array}$ & $\begin{array}{c}0 \cdot 19 \\
(0 \cdot 29)\end{array}$ & $\begin{array}{c}0.23 \\
(0 \cdot 01)\end{array}$ & $\begin{array}{c}0.18 \\
(0.01)\end{array}$ \\
\hline & $<75 \%$ & 3062 & $\begin{array}{c}-0.23 \\
(0.22)\end{array}$ & $\begin{array}{c}-0.09 \\
(0.21)\end{array}$ & $\begin{array}{c}0.48 \\
(0.03)\end{array}$ & $\begin{array}{c}0.03 \\
(0.02)\end{array}$ & $\begin{array}{c}0.23 \\
(0.01)\end{array}$ & $\begin{array}{c}0.19 \\
(0.01)\end{array}$ \\
\hline Full dataset & None & 11919 & $\begin{array}{c}-0.02 \\
(0.06)\end{array}$ & $\begin{array}{c}-0 \cdot 10 \\
(0.06)\end{array}$ & $\begin{array}{c}0.53 \\
(0.03)\end{array}$ & $\begin{array}{c}0.21 \\
(0.02)\end{array}$ & $\begin{array}{c}0.26 \\
(0.01)\end{array}$ & $\begin{array}{c}0.22 \\
(0.01)\end{array}$ \\
\hline \multirow[t]{4}{*}{ Ascites resistant } & $>60 \%$ & 11506 & $\begin{array}{c}-0.04 \\
(0.06)\end{array}$ & $\begin{array}{c}-0.12 \\
(0.06)\end{array}$ & $\begin{array}{c}0.54 \\
(0.03)\end{array}$ & $\begin{array}{c}0 \cdot 16 \\
(0.02)\end{array}$ & $\begin{array}{c}0.26 \\
(0.01)\end{array}$ & $\begin{array}{c}0.22 \\
(0.01)\end{array}$ \\
\hline & $>80 \%$ & 6499 & $\begin{array}{c}0.16 \\
(0.13)\end{array}$ & $\begin{array}{r}-0.02 \\
(0.12)\end{array}$ & $\begin{array}{c}0.50 \\
(0.03)\end{array}$ & $\begin{array}{c}0.04 \\
(0.01)\end{array}$ & $\begin{array}{c}0.24 \\
(0.01)\end{array}$ & $\begin{array}{c}0.20 \\
(0.01)\end{array}$ \\
\hline & $>85 \%$ & 3871 & $\begin{array}{c}0.08 \\
(0 \cdot 17)\end{array}$ & $\begin{array}{c}0 \cdot 10 \\
(0 \cdot 16)\end{array}$ & $\begin{array}{c}0.48 \\
(0.03)\end{array}$ & $\begin{array}{c}0.04 \\
(0.02)\end{array}$ & $\begin{array}{c}0.24 \\
(0.01)\end{array}$ & $\begin{array}{c}0 \cdot 19 \\
(0 \cdot 01)\end{array}$ \\
\hline & $>90 \%$ & 1299 & $\begin{array}{c}0.29 \\
(0.32)\end{array}$ & $\begin{array}{c}0.07 \\
(0.28)\end{array}$ & $\begin{array}{c}0.47 \\
(0.03)\end{array}$ & $\begin{array}{c}0.04 \\
(0.05)\end{array}$ & $\begin{array}{c}0.23 \\
(0.01)\end{array}$ & $\begin{array}{c}0.18 \\
(0.01)\end{array}$ \\
\hline
\end{tabular}

${ }^{1}$ The original data set was divided on the basis of $\mathrm{SaO}$ measures to separate ascites-susceptible from ascites-resistant birds. $n$ is the number of birds with records per subset of data. 
interpret in that the estimation of parameters was carried out for the trait used to create the subsets of data. Anyhow, if these effects were real, they would have an impact on the success of programs aiming to improve $\mathrm{SaO}$ and production traits simultaneously.

McMillan and Quinton (2002) conducted a simulation study to assess the changes in ascites incidence when selection was performed on body weight alone or also on an ascites indicator trait, under a variety of scenarios. They concluded that selection for improved growth and reduced ascites could be effective, more so if an indicator trait was used together with sib information prior to selection for growth, but noticed that this reduced gain in the latter trait. The authors showed that the higher the correlation of the indicator trait with ascites, the greater was the genetic reduction of the population's ascites susceptibility. We do not have estimates of correlations between $\mathrm{SaO}$ and ascites incidence in our populations, but Druyan et al. (1999) estimated that the genetic correlation of $\mathrm{SaO}$ with ascites mortality was around $-0 \cdot 50$. McMillan and Quinton (2002) also observed that a reduction in the genotypic mean of ascites susceptibility did not always translate into a decrease in the incidence of the disorder, but rather the opposite, and suggested that this was an effect of added metabolic pressure of the improvement in growth potential and therefore a change in the internal environment of the birds. However, this result could depend on the model used in their simulations.

Finally, Figure 2 shows that, although heritabilities for $\mathrm{SaO}$, Weight and Flesh were similar for line 3, and genetic progress was being made for the three traits studied, improvement was more pronounced for production traits. This could be a consequence of breeding strategies but could also be caused by a failure of the models used to adequately describe the genetic architecture of the traits studied and their genetic relationships. The exploration of the data using more complex models (including, for example, a locus or several loci with large effect, in addition to a polygenic component) may give a better insight of the genetic architecture of $\mathrm{SaO}$ and its relationship with Weight and Flesh. If such loci existed, their identification could make the reduction of ascites incidence in broiler flocks an easier task, allowing for direct manipulation of allele frequencies at this locus or loci, therefore bypassing potential problems due to effects of allele, gene or genotype $\mathrm{x}$ environment interactions that could hinder the effectiveness of more traditional selection methods.

\section{ACKNOWEDGEMENTS}

We acknowledge support from the Biotechnology and Biological Sciences Research Council. PN is also grateful to Aviagen Ltd. for funding.

${ }^{1}$ Criticare Systems Inc., Milwaukee, USA, supplied by R.L. Dolby, Stirling, UK.

\section{REFERENCES}

De Greef, K.H., Janss, L.L.G., Verejjken, A.L.J., Pit, R. \& Gerritsen, C.L.M. (2001) Disease-induced variability of genetic correlations: ascites in broilers as a case study. Journal of Animal Science, 79: 1723-1733.

Druyan, S., Cahaner, A., Bellaiche, M., Rosner, A. \& ShlosberG, A. (1999) Genetic evaluation of blood oxygenation, heart rate, electrocardiographic (ECG) waveforms, and their association with ascites in broilers. Poster at the European Poultry Breeders Roundtable, Wiesensee, Germany.

Dunnington, E.A. \& Siegel, P.B. (1996) Long-term divergent selection for eight-week body weight in white Plymouth Rock chickens. Poultry Science, 75: 1168-1179.

Emmerson, D.A. (1997) Commercial approaches to genetic selection for growth and feed conversion in domestic poultry. Poultry Science, 76: 1121-1125.

GENSTAT 5 COMMITTEE (1993) GenstatTM 5 Release 3 Reference Manual, (Oxford, UK, Clarendon Press).

Gilmour, A.R., Cullis, B.R., Welham, S.J. \& Thompson, R. (2000) ASREML Reference Manual. 2nd ed. Release 1.0 NSW Agriculture Biometrical Bulletin 3. (Orange (Australia)) ftp://ftp.res.bbsrc.ac.uk/pub/aar/.

Havenstein, G.B., Ferket, P.R. \& Qureshi, M.A. (2003) Growth, livability, and feed conversion of 1957 versus 2001 broilers when fed representative 1957 and 2001 broiler diets. Poultry Science, 82: 1500-1508.

Hitl, W.G. (1996) Mutations and selection response in quantitative traits, in: Proceedings of the National Breeder's Roundtable Meeting. St. Louis, MO.

HiLl, W.G. (2002) Direct effects of selection on phenotypic variability of quantitative traits. CD-ROM communication $\mathrm{n}^{\circ}$ 19-02 in Proceedings of the 7th World Congress on Genetics Applied to Livestock Production. Montpellier, France.

Julian, R.J. (1993) Ascites in poultry. Avian Pathology, 22: 419-454.

Julian, R.J. \& Mirsalimi, S.M. (1992) Blood-oxygen concentration of fast-growing and slow-growing broiler-chickens, and chickens with ascites from right ventricular failure. Avian Diseases, 36: 730-732.

Koerhuis, A.N.M. \& Thompson, R. (1997) Models to estimate maternal effects for juvenile body weight in broiler chickens. Genetics Selection Evolution, 29: 225-249.

Lubritz, D.L., Smith, J.L. \& Mcpherson, B.N. (1995) Heritability of ascites and the ratio of right to total ventricle weight in broiler breeder male lines. Poultry Science, 74: 1237-1241.

Maxwell, M.H., Robertson, G.W., Bautista-Ortega, J. \& Hocking, P.M. (1998) A preliminary estimate of the heritability of plasma Troponin $\mathrm{T}$ in broiler chickens. British Poultry Science, 39: 16-19.

McMillan, I. \& Quinton, V.M. (2002) Selection strategies for limiting the increase in ascites while increasing growth in broilers. Poultry Science, 81: 737-744.

Moghadam, H.K., McMillan, I., Chambers, J.R. \& Julian, R.J. (2001) Estimation of genetic parameters for ascites syndrome in broiler chickens. Poultry Science, 80: 844-848.

Pakdel, A., van Arendonk, J.A.A., Vereijken, A.L.J. \& Bovenhuis, H. (2002) Direct and maternal genetic effects for ascites-related traits in broilers. Poultry Science, 81: $1273-1279$. 
Pakdel, A., van Arendonk, J.A.M., Vereijken, A.L.J. \& Bovenhuis, H. (2005) Genetic parameters of ascites-related traits in broilers: effect of cold and normal temperature conditions. British Poultry Science, 46: 35-42.

Rose, S.P. (1997) Principles of Poultry Science, 1st edn (Oxon, UK, CAB International).

Self, S.G. \& Liang, K.Y. (1987) Asymptotic properties of maximum-likelihood estimators and likelihood ratio tests under nonstandard conditions. Journal of the American Statistical Association, 82: 605-610.

Wideman, R.F., Wing, T., Kirby, Y.K., Forman, M.F., Marson, N., Tackett, C.D. \& Ruiz-Feria, C.A. (1998) Evaluation of minimally invasive indices for predicting ascites susceptibility in three successive hatches of broilers exposed to cool temperatures. Poultry Science, 77: 1565-1573. 